\title{
Finansal Okuryazarlık ve Üniversitede Verilen Derslerin Finansal Okuryazarlık Üzerine Etkisi
}

\author{
Financial Literacy and The Effect of Courses on University on \\ Financial Literacy
}

\author{
Süleyman Uyar $^{1}$ (D), Işıl Atalay² (D) \\ 'Prof. Dr., Alanya Alaaddin Keykubat Üniversitesi, İktisadi ve İdari Bilimler Fakültesi, İşletme Bölümü, Antalya, Türkiye \\ ${ }^{2}$ Doktora Öğrencisi, Alanya Alaaddin Keykubat Üniversitesi, İşletme Ana Bilim Dalı, Antalya, Türkiye
}

ORCID: S.U. 0000-0001-7895-1779; I.A. 0000-0003-2690-2144

\section{ÖZ}

Günümüzde gelişen bilgi teknolojileri ve finansal sistemler hayatımızın her alanını etkilemektedir. Sıradan bir vatandaşın bile finansal okuryazarlık bilgisi hayata dair alacağı bazı finansal kararları olumlu etkilemektedir. Bu bağlamda kişilerin finansal okuryazarlık seviyesinin tespit edilmesi önem arz etmektedir. Bu çalışmada üniversite öğrencilerinin finansal okuryazarlık durumlarını incelemek amacıyla Alanya Alaaddin Keykubat Üniversitesi İktisadi ve İdari Bilimler Fakültesi’nde (İIBF) okuyan öğrencilerin finansal okuryazarlık düzeyi araştırılmıştır. Ayrıca finansal okuryazarlık düzeyinin, konuya ilişkin verilen derslerden etkilenme düzeyi ve öğrencilerin eğitime ilişkin düşünceleri gibi farklı değişkenlerden nasıl etkilendiği de ölçülmüştür. Çalı̧̧madan elde edilen bulgulara göre; öğrencilerin aldıkları dersler ile cinsiyetleri finansal okuryazarlık düzeyini etkilememektedir. Buna karşın öğrencilerin kendi finansal okuryazarlıklarına yönelik değerlendirmeleri, okuduğu sınıf ve not ortalaması finansal okuryazarlık düzeyini etkilemektedir. Çalışmadan elde edilen bulgular genel anlamda öğrencilerin finansal okuryazarlık seviyesinin düşük olduğunu göstermektedir.

Anahtar kelimeler: Finansal okuryazarlık, üniversite öğrencileri, finansal okuryazarlık düzeyi

\section{ABSTRACT}

Today, developing information technologies and financial systems affect every area of our lives. Financial literacy knowledge, even that ordinary citizens, positively affects some of the financial decisions that they will make regarding their lives. In this context, it is important to determine the financial literacy level of individuals. In this study, the financial literacy level of students studying at Alanya Alaaddin Keykubat University Faculty of Economics and Administrative Sciences (İ.İ.B.F.) was investigated in order to examine the financial literacy status of university students. In addition, how the level of financial literacy was affected by different variables such as the level of being affected by the lessons given on the subject and the students' opinions about education, was also measured. According to the findings obtained from the study, students' lessons and gender do not affect the level of financial literacy. Rather, financial literacy levels are affected by students' self-evaluation of their own financial literacy, the grades they have studied and GPA. Findings obtained from the study generally show that students' financial literacy level is low.

Keywords: Financial literacy, university students, financial literacy level

Başvuru/Submitted: 25.06.2020 Revizyon Talebi/Revision Requested: 12.09.2020 Son Revizyon/Last Revision Received: 26.10 .2020 Kabul/Accepted: 02.11.2020 Sorumlu yazar/Corresponding author: Süleyman Uyar / suleyman.uyar@alanya.edu.tr 


\section{Extended Abstract}

Today, developing information technologies and financial systems affect every area of our lives. Financial literacy knowledge, even that of ordinary citizens, positively affects some of the financial decisions that they will make regarding their lives. Financial education in the process of gaining financial literacy; It plays a role in providing individuals with financial information, skills and skills infrastructure and supporting the process (Mason \& Wilson, 2000). In this context, it is important to determine the financial literacy level of individuals. Research on university students has gained importance in determining the financial literacy levels of young individuals (Yew et al., 2017, s.45). The effect of financial education given at universities is intriguing and various studies have been carried out in many different countries. In studies conducted with different variables, it was found that male students had higher financial knowledge compared to female students and students in departments with financial education at the university had higher financial knowledge compared to students in other faculties (Volpe et al., 1996, s.92). In particular, there have been studies focusing on students studying in departments with dense financial courses such as business and economics. In these studies, it was concluded that financial literacy levels of students studying in business and economics departments, where financial lessons are intense, were higher than other departments (Beal \& Delpachitra, 2003, p.77; Borden et al., 2008, p. 35; Rosacker at al., 2009, p.391; Luksander at al., 2014, p.240; Kozina \& Ponikvar, 2015, p.252; Chen \& Volpe, 1998, p. 222). However, it has been stated that the level of financial knowledge increased gradually from the first year of education to the last year, thereby positively affecting students' financial attitudes and behaviors (Jorgensen \& Savla, 2010, p. 476).

In Turkey, several studies were conducted in order to measure the impact of the financial literacy level of financial education of university students. While some of these studies mostly focused on the interaction of students' financial knowledge and financial attitudes and behaviors (Coşkun, 2016; Alkaya \& Yağl1, 2015; Sarıgül, 2015; Çam \& Barut, 2015), another part is their demographic and socio-economic characteristics ( Barmak1 \& Şener, 2017) and studies to determine the level of financial literacy (Ergün, et al., 2014; Kiliç, et al., 2015; Çinko et al., 2017). In addition, quantitative studies (Bayram, 2014; Er et al., 2014; Elmas \& Y1lmaz, 2016) and qualitative (Güvenç, 2017) have been conducted on the content of university education and programs, and the effects of financial courses on financial literacy. In the aforementioned studies, the authors tried to determine whether the financial literacy levels of the students were affected by variables such as faculty, department, and academic year.

In this study, conducted with students studying at Alanya Alaaddin Keykubat University Faculty of Economics and Administrative Sciences, the variables were the following: gender, department, grade, grade point average, grade point average, their opinions about the courses on financial education at the university and the students' assessment of their own financial literacy. These dependent variables are classified as $0=$ financially literate, $1=$ financially illiterate. Logistic regression analysis will reveal the effect of independent variables in predicting the membership of students to groups classified as financially literate and financially illiterate. This analysis will reveal the effect of independent variables in predicting students' membership of the groups classified as financially illiterate and financially literate. All the selected independent variables were defined categorically, and the first levels were selected as the reference class for all variables including the dependent variable. In $90 \%$ of the literature studies on financial literacy and its measurement, a standard indicator that the individuals subjected to the research are financially literate could not be obtained, and in the rest of the studies, a further threshold value was used in measuring and interpreting financial literacy (Huston, 2010, p. 303). In the study, whether the students are financially literate or not was determined with the help of a threshold value, and it was deemed appropriate to determine the median value of the correct answer score given to the questions measuring financial information as the threshold value (Volpe, et al., 1996; Chen \& Volpe, 1998; Volpe, Kotel, \& Chen, 2002. ; Beal and Delpachitra, 2003; Suwanaphan, 2013). Accordingly, students with literacy score higher than the median score (55.55\%) were coded with 1. 1-p is the low level of financial literacy of the student and students with literacy score equal to or lower than the median score (55.55\%) are coded with 0 . The ratio of students who can be defined as financially literate to faculty students is calculated as $26 \%$. 
According to the findings obtained from the study, the gender was not statistically significant in estimating the probability of being financially literate. The conclusion that the students who had successfully completed the first year would be financially literate corresponds with studies concluding that the level of financial knowledge increased after the end of the first year of education. This means that the six-hour basic financial education requirement of all department students, especially if completed in the first year, significantly increases the probability of being financially literate. However, it has been concluded that the fact that students receive education in different departments does not affect the possibility of advanced financial literacy, contrary to the results obtained in other studies. It was concluded that the students' education in the Business Department, which was taken as the reference group, did not affect the financial literacy level compared to other departments. Although the compulsory financial course hours are different in the curriculum of the department, this difference was not effective at the level of financial literacy. It was also concluded that students with higher grades are less likely to be financially literate than reference group students with low grade point averages. This means that students with a GPA of 2.5 and 2.99 in the faculty have a higher GPA than other subjects. In other words, the reason why students with a high GPA are more successful than unsuccessful students is the course rather than financial content. In addition, it was determined that the courses given in the faculty did not affect the financial literacy situations of the students, which they thought were effective or otherwise. However, it was concluded that students' perception of themselves as being financially literate affects the probability of them being financial literate. 


\section{Giriş}

Piyasaların dinamikliği karşısında finansal kararların alınması ve uygulanması giderek karmaşıklaşmaktadır. Devletler, işletmeler ve bireyler tarafından varlıkların en etkin şekilde yönetilmesi, varlık edinebilmek kadar önemli hale gelmiştir. Piyasaya ve günlük hayata yönelik finansal müdahaleler devlet, işletmeler ve bireylerce gerçekleştirilebilir. Bu eylemler devlet tarafından kamu maliyesi, işletmeler tarafından işletme finansı ve tüketici tarafından ise kişisel/bireysel finans olarak sınıflandırılabilir (Danes ve Hira, 1987, s.4). Tüketici bağlamında emeklilik, çocukların eğitimi, hayat ve sağlık sigortası, konut edinme gibi uzun vadeli yatırımlar, artan hane halkı borcu ve kısa vadeli tasarruflar gibi durumlar nedeniyle özellikle 90'lı yıllardan itibaren kişisel finansı yönetme yeteneğine giderek daha çok ihtiyaç duyulmuştur (Chen ve Volpe, 1998, s.107). Bu bağlamda bireylerin öngörüde bulunarak varlıklarını bilinçli olarak yönetebilme, efektif karar alma ve davranışlarda bulunabilme yeteneği finansal okuryazarlık olarak adlandırılabilir (Noctor, Stoney ve Stradling, 1992, s.21).

Finansal okuryazarlık için buna benzer standart bir tanımlama yapmak bazen yetersiz kalmaktadır. Örneğin, finansal okuryazarlık genellikle bir tür tüketici uzmanlığı olarak görülebilir. Bu uzmanlık, bireyin mali işlerini başarılı bir şekilde nasıl yönettiğine (Alba ve Hutchinson, 1987, s.411) ya da kişisel finansa dayalı insan sermayesi olarak açıklanmaktadır (Fernandes, Jr. ve Netemeyer, 2014, s.1862). Bir başka tanımlama ile finansal okuryazarlık olayları ve değişen ekonomik koşulları göz önünde bulundururken kişinin temel finansal kavramları anlaması, uygun kısa vadeli karar verme ve sağlam uzun vadeli finansal planlamayı başararak kişisel finansları yönetme yeteneğidir (Remund, 2010, s.284). Bu tanımlamalara ek olarak Ekonomik Kalkınma ve İşbirliği Örgütü (OECD, 2011) tarafından yapılan tanıma göre finansal okuryazarlık, etkin finansal kararlar vermek ve böylece bireysel finansal refahı elde etmek için gereken farkındalık, bilgi, yetenek, tutum ve davranışın bir birleşimidir. Tanımlamalardan yola çıkarak finansal okuryazarlık konusunda öncelikle bireyin; a) finansal kavramları içeren bilgiyi edinmesi, b) edindiği bilgiyi algılaması ve c) ardından öngörü ve yeteneği ile karar alarak bu bilgiyi davranışa dönüştürmesi gerekir (Hung, Parker ve Yoong, 2009, s.708; Remund, 2010, s.279).

Finansal okuryazarlık, "anlamlandırma yaratan bir süreç" olarak görülmektedir. Buna göre finansal okuryazarlı̆̆ın edinilmesinde; bireylerin yetenekleri/teknolojiler, bilgi kaynakları, finansal deneyim ve beklentilerin kombinasyonunu kullandıkları bir süreçten söz edilmektedir (Mason ve Wilson, 2000, s.22).

Finansal okuryazarlık, finansal dünyanın artan karmaşıklığına karşı sağduyulu ve açık bir yanıtlama biçimi olup (Fernandes, Jr., ve Netemeyer, 2014), kişisel finansal kararların alınmasında ve refahın artırılmasında önemli bir unsurdur (Nidar ve Bestari, 2012, s.163). Öyle ki, ABD Temsilciler Meclisi Finansal Hizmetler Komitesi’ne göre (2009), tüketicilerin finansal okuryazarlık düzeyinde artı̧̧ı sağlanması, kamu refahının yükselmesi için bir politika hedefi olarak kabul edilmiştir. Aksi halde finansal okuryazarlık seviyesinin düşük olması durumunda, yüksek hane halkı ve bireysel borçlar, verimsiz mali kararlar (Lusardi ve Tufano, 2015) yetersiz emeklilik planlaması (Lusardi ve Mitchelli, 2007, s.35) ve yüksek enflasyonist beklenti (Bruin, Vanderklaauw ve Downs, 2010, s.381) gibi sosyo-ekonomik açıdan olumsuz sonuçlarla ilişkilendirilmektedir (Cull ve Whitton, 2011, s.99).

Kişisel finansal okuryazarlık seviyesini etkileyen iç (kişisel özellikler) ve dış (çevre) faktörler bulunmaktadır (Nidar ve Bestari, 2002, s.163). Parayı değerlendirme bilgi ve becerisi olarak düşünüldüğünde finansal okuryazarlık hem iç hem de dış faktörlerin etkileşiminden meydana gelecektir. Söz konusu faktörler aşağıda sıralanmıştır:

- Kişisel demografik özellikler (Chen ve Volpe, 2002, s.291; Worthington, 2006, s.59; Beal ve Delpachitra, 2003, s.65; Cude ve ark., 2006, s.102).

- Finansal deneyim (Mandell, 2006, s.4; Peng, Bartholomae, Fox ve Cravener, 2007, s.265).

- Beklentiler (Mandell, 2008, s.15).

- Ailevi özellikler (Mandell, 2008, s.12; Mitchell, Lusardi ve Curto, 2009, s.1).

- Coğrafi konum (Mandell, 2008, s.41). 
- Sosyal ve ekonomik özellikler ve ekonomik koşullar (Worthington, 2006, s.62).

- Finansal eğitim (Mandell, 2008, s.11; Peng ve ark., 2007, s.265).

Finansal okuryazarlıkla ilgili bilgi ve becerinin kazanılması da önemli bir unsurdur. Finansal okuryazarlığın kazanılması sürecinde finansal eğitim; bireylere finansal bilgi, yetenek ve beceri altyapısını sağlayacak ve süreci destekleyici rol oynayacaktır (Mason ve Wilson, 2000). Finansal eğitim kavramı; finansal ürünler, kavramlar, riskler ve fırsatlara ilişkin bilgi ve farkındalık yaratarak bireyde etkin karar verme ve refah artışı yaratma becerileri oluşturmanın da ötesinde finansal bilgi ve tavsiyelerden fazlasını gerektirir. Öyle ki finansal eğitim, özellikle politika uygulayıcılar için tüketicilerin finansal hareketlerinde artan karmaşıklığa karşı hayati bir panzehir olarak benimsenmiştir (Fernandes, Jr. ve Netemeyer, 2014, s.1862). OECD tarafından finansal eğitim ve farkındalığa ilişkin yayımlanan raporda sunulan öneriler aşağıdaki gibidir (OECD, 2005):

- Finansal kapasite geliştirilmeli, finansal eğitim adil ve tarafsız bir şekilde sağlanmalı, düzenlenmeli ve geliştirilmelidir.

- Finansal eğitim programları temel finansal matematik ve ekonomi konularını içermeli, buna ek olarak temel tasarruf, özel borç yönetimi veya sigorta gibi finansal yaşam planlamasının önemli yönleri hakkında bilgilendirme içermelidir.

- Finansal eğitim; finansal kurumların düzenlenmesi ve tüketicinin korunmasına ek olarak ekonomik güven ve istikrarı teşvik etmek için bir araç olarak görülmeli, düzenleyici ve idari çerçevede yer edinmelidir.

- Finansal eğitim programları, hedef kitlelerinin ihtiyaçlarını karşılayacak ve hedef kitlelerinin finansal bilgi alma biçimine yönelik tercihleri yansıtacak şekilde tasarlanmal, yaşam boyu devam eden sürekli bir süreç olarak görülmelidir.

- Bireyler finansal konularla hayatlarında mümkün olan en erken zamanda tanışmalı, finansal eğitim okulda başlamalıdır.

- Finansal eğitimin, devlet yardım programlarının bir parçası olması konusuna özen gösterilmelidir.

- Mevcut finansal eğitim programlarına ilişkin ölçüm ve değerlendirme için yöntemlerin geliştirilmesi teşvik edilmeli, ilgili kriterleri karşılayan finansal eğitim programları dikkate alınmalıdır.

\section{Literatür Araştırması}

Finansal okuryazarlık konusunda yapılan birçok çalışma bulunmaktadır. Bu çalışmalardan bazıları ve çalışmalardan elde edilen bulgular aşağıda özetlenmiştir.

Seçilmiş ülkelere yönelik gerek bütüncül gerek mukayeseli araştırmalarda finansal okuryazarlık seviyeleri arasında genç yetişkinlerin en düşük seviyelerde olduğu gösterilmektedir (OECD, 2020). Öte yandan, günümüzde finansal sistemlerin geçmişe kıyasla farklı ve karmaşık hal alması, refahtaki azalışa karşın yaşam beklentilerindeki artış, istihdam sorunları, ekonomideki belirsizlikler gibi sebeplerden dolayı gençlerin finansal okuryazarlık düzeylerinin geliştirilmesine yönelik müdahaleler en temel konulardan biri haline gelmiştir (Atkinson ve Messy, 2012, s.49). Öyle ki, finansal kavramlarla başa çıkma, genellikle bireyin aile evinden ayrılarak kendi başına yaşamaya başladığı dönemde ihtiyaç olarak daha da belirginleşmektedir. Böylece bireyler kendi ailelerini kurma ya da emeklilik planlamalarından daha önce, büyük harcama ve borç miktarları oluşturabilecek yaşam olaylarına başladıkları ve sorumluluklar üstlendikleri için üniversite döneminde finansal okuryazarlık düzeylerince gelişmişlik sağlamalıdır (Cull ve Whitton, 2011, s.99). Bu bağlamda finansal okuryazarlık düzeylerini saptayabilme açısından üniversite öğrencilerine yönelik araştırmalar önem arz etmektedir (Yew, Yong ve Cheong, 2017, s.45).

Üniversite öğrencilerinin finansal okuryazarlık düzeyleri, birtakım farklı değişkenlerle test edilerek belirlenmeye çalışılmıştır. Chen ve Volpe tarafından üniversite öğrencilerinin finansal okuryazarlık seviyelerini belirleme ve karşılaştırma amacıyla bir çalışma yapılmıştır. Çalışmada yaş, cinsiyet gibi demografik özellikler, iş deneyimleri, finansal içerikli ders almış olma gibi değişkenlerin finansal okuryazarlık düzeyinde etkili olduğu gözlemlenmiştir. Ayrıca daha fazla iş tecrübesi 
olan katılımcıların, 20-29 yaş, 40 yaş ve üstü katılımcıların diğer katılımcılara kıyasla daha fazla finansal okuryazarlık bilgisine sahip olduğu gözlemlenmiştir (Chen ve Volpe, 1998, s.121). Beal ve Delpachitra benzer şekilde iş deneyimi ve gelir düzeyi arttıkça finansal okuryazarlık seviyesinin de yükseldiğini ortaya koymuşlardır. Avustralyalı öğrenciler üzerinde gerçekleştirilen bu çalışmada üniversite öğrencilerinin finansal bilgi ve becerilerinin yetersiz olduğu tespit edilmiştir (Beal ve Delpachitra, 2003, s.77). Agarwal ve arkadaşları finansal okuryazarlık düzeyinin yaş ile pozitif ilişki içinde olduğunu tespit emiştir. Bunu yaştaki artış ile gelen yaşam deneyimlerine ve bilgi birikimine dayandırmış, daha fazla yaş artışı ile görülen negatif ilişkiyi ise bilişsel işlevlerin kötüleşmesi olarak yorumlamışlardır (Agarwal, Driscoll ve Gabaix, 2009, s.75).

Finansal okuryazarlık ile ailevi etki ilişkisine yönelik çalışmalar da bulunmaktadır. Cude ve arkadaşları (2006) üniversite öğrencilerinin finansal bilgilerinin yetersiz olduğunu saptamakla birlikte ebeveynlerin finansal sosyalleşmede etkili olduklarını ileri sürmüştür. (Cude ve ark., 2006, s.107). Benzer şekilde Jorgensen ve Savla (2010) genç bireylerin finansal okuryazarlık düzeylerini ailevi etki yönünden araştırmışıı. Araştırma sonucunda ailelerin finansal tutum üzerinde doğrudan, finansal davranış üzerinde ise finansal tutum kaynaklı dolaylı etkisi olduğu, finansal bilgi konusunda ise etkisi olmadığına ulaşmışlardır (Jorgensen ve Savla, 2010, s.475). Xiao ve arkadaşları üniversite eğitimine yeni başlamış öğrencilerin aile, çalışma ve eğitim durumları ile finansal öğrenme, tutum ve davranışları arasındaki ilişkiyi araştırmış ve ailevi etkinin oldukça önemli olduğu sonucuna ulaşmışlardır (Xiao, Shim, Barber ve Lions, 2007, s.11). Razafimahasolo ve arkadaşları ise tüm bu çalışmaların aksine bulguların yaş, cinsiyet ve aile gelirinden bağımsız olduğunu tespit etmişlerdir. Ortanın üzeri finansal okuryazarlığa sahip ve nakit yönetiminde başarılı olan öğrencilerin düşük stres seviyesi ve yüksek akademik başarıya sahip oldukları bulunmuş, finansal okuryazarlığın düşük olduğu durumlarda ise stresin arttığı, akademik başarının da düştüğü tespit edilmiştir (Razafimahasolo, Borromeo ve Sausa, 2016, s.34).

Üniversite öğrencilerine yönelik yapılan finansal okuryazarlık çalışmalarına ilişkin bulgularda cinsiyet değişkeninin etkili olduğu da öne sürülmüsşür (Danes ve Hira, 1987, s.15; Chen ve Volpe, 1998, s.114; Worthington, 2006, s.73; Chen ve Volpe, 2002, s.214; Dvorak ve Hanley, 2010, s.650; Markovich ve DeVaney,1997, s.61; Furtuna, 2007, s.20; Kılıç, Ata ve Seyrek, 2015, s.140; Kocabıyık ve Teker, 2018, s.143; Şamiloğlu, Kahraman ve Bağc1, 2016, s.312; Ergün, Şahin ve Ergin, 2014, s.855). Bu çalı̧̧malarda çoğunlukla erkeklerin finansal okuryazarlık seviyesinin ya da bilgisinin kadınlara kıyasla daha yüksek olduğu belirlenmiştir. Bu durum kadınların finansal risk tutumları yönünden erkeklere kıyasla finansal riskten kaçınma eğilimlerinin daha yüksek olması ile açıklanmıştır (Coleman, 2003, s.111). Öte yandan bazı çalışmalarda cinsiyet ile finansal okuryazarlık bilgi veya düzeyi arasında herhangi bir ilişki bulunmadığı sonucuna ulaşılmıştır (Adeleke, 2013, s.40; Jorgensen ve Savla, 2010; Rosacker ve Rosacker, 2016; Razafimahasolo ve ark., 2016; Barış, 2016; Ludlum, Tilker, Ritter, Cowart ve Xu, 2012, s.30).

Üniversite öğrencilerinin kredi kartı kullanımının finansal okuryazarlık düzeyinde bir etken olabileceği düşünülmüş ve bu konuda da çeşitli araştırmalar yapılmıştır. Örneğin ABD.'de üniversite öğrencilerinin kredi kartı kullanımı ve finansal bilgi düzeyi arasındaki iliş̧i incelenmiş ve anlamlı bulunmuştur (Robb, 2011, s.690). Yine A.B.D.'de öğrencilerin \%70’inin bir adet, \%36'sının ise en az bir adet kredi kartı kullandığı, bunlardan yalnızca \%10'unun gecikme cezası, kart faizi ve benzeri konularda bilgili oldukları tespit edilmiştir. Öğrencilerin finansal bilgi düzeyi ile kredi kartı borçlanma davranışları arasındaki ilişki araştırılmış ve finansal okuryazarlık düzeyi yüksek öğrencilerin kredi kartı borçlanma davranışlarında daha dengeli ve dikkatli oldukları tespit edilmiştir (Robb ve Sharpe, 2009, s.25). Bir başka çalışmada ise bilgi düzeylerinin gerek kredi kartı kullanımında gerekse ödeme alışkanlıklarındaki riski düşürdüğü belirtilmiştir (Xiao, Ahn, Serido ve Shim, 2014, s.596).

Genç bireylerin finansal okuryazarlık edinimi hususunda üniversitede verilen finans eğitiminin etkisi merak uyandırmakta, birçok farklı ülkede çeşitli çalışmalar yapılmaktadır. Volpe ve arkadaşlarının araştırması bu konunun öncüllerindendir. Farklı demografik değişkenlerle gerçekleştirilen çalışmada erkek öğrencilerin kadın öğrencilere kıyasla ve üniversitede finansal eğitim içeren bölümlerdeki öğrencilerin diğer fakültelere kıyasla daha yüksek finansal bilgi düzeyine sahip olduğu sonucuna ulaşılmıştır (Volpe, 1996, s.92). Finansal okuryazarlık düzeyini belirleme ve karşılaştırma amacıyla yapılan bir başka çalışmada benzer şekilde finansal içerikli ders gören, okula kayıt tarihi eski olan öğrencilerin finansal okuryazarlık seviyeleri daha yüksek olarak belirlenmiştir. Finansal bilgi düzeyi ve finansal bilgiye yönelik görüş ve davranışlarda pozitif 
yönlü ilişki saptanmıştır (Chen ve Volpe, 1998, s.122). Özellikle işletme ve iktisat gibi finansal içerikli derslerin yoğun olduğu bölümlerde okuyan öğrenciler üzerine yoğunlaşan çalışmalar da bulunmaktadır. Bu çalışmalarda finansal içerikli derslerin yoğun olduğu işletme ve iktisat bölümlerinde eğitim gören öğrencilerin finansal okuryazarlık düzeylerinin, diğer bölümlere göre daha yüksek olduğu sonucuna ulaşılmıştır (Beal ve Delpachitra, 2003, s.77; Borden, Sun-A Lee ve Collins, 2008, s.35; Rosacker, Ragothaman ve Gillispie, 2009, s.391; Luksander, Béres ve Huzdik, 2014, s.240; Kozina ve Ponikvar, 2015, s.252). Bununla birlikte finansal bilgi düzeyinin eğitime ilk başlanılan yıldan son yıla doğru aşamalı bir artış gösterdiği, dolayısıyla finansal tutum ve davranışları da pozitif biçimde etkilediği belirtilmiştir (Jorgensen ve Savla, 2010, s.476).

Türkiye'de finansal eğitimin, üniversite öğrencilerinin finansal okuryazarlık düzeyine etkisini ölçme amacıyla çeşitli çalışmalar gerçekleştirilmiştir. Bunların bir kısmı daha çok öğrencilerin finansal bilgi düzeyi ile finansal tutum ve davranışların etkileşimine odaklı çalışmalar (Coşkun, 2016; Alkaya ve Yağlı, 2015; Sarıgül, 2015; Çam ve Barut, 2015) ile demografik ve sosyo-ekonomik özelliklere göre (Barmakı ve Şener, 2017) finansal okuryazarlık düzeyini belirlemeye yönelik çalışmalardan (Ergün, ve ark., 2014; K1lı̧ ve ark., 2015; Çinko, Avcı, Ergun, ve Tekçe, 2017) oluşmaktadır. Bununla birlikte üniversite eğitimi ve programların içeriği ile finansal derslerin etkisine yönelik nicel (Bayram, 2014; Er, Temizel, Özdemir ve Sönmez, 2014; Elmas ve Yılmaz, 2016) ve nitel (Güvenç, 2017) araştırmalar da yapılmıştır. Söz konusu çalışmalarda öğrencilerin finansal okuryazarlık düzeylerinin öğrenim gördükleri fakülte, bölüm, sınıf gibi değişkenlerden etkilenip etkilenmediği ortaya konmaya çalışılmıştır.

Sınıf veya öğrenim türüne göre öğrencilerin finansal bilgi düzeyindeki farklılıkları belirlemeye yönelik yapılan çalışmalarda sınıf ve öğrenim türü faktörlerinin bilgi seviyelerinde önemli farklılıklara sebep olduğu saptanmıştır (Tuna ve Ulu, 2016). Benzer şekilde Gümüş ve Pailer tarafından işletme bölümü öğrencileri üzerinde gerçekleştirilen çalışmada hiç finans dersi almamış birinci sınıf öğrencileri ile finans dersini başarı ile tamamlamış sonuncu sınıf öğrencileri arasındaki farklılıklar saptanmıştır. Finansal bilgi ve davranış konusunda sonuncu sınıflar daha yüksek düzeyde ve etkin iken ilk sınıfların finansal algı düzeyi son sınıflardan daha yüksek olarak ölçülmüştür (Gümüş ve Pailer, 2019). Erciyes Üniversitesi’nde gerçekleştirilen bir diğer çalışmada işletme bölümü ve diğer bölümlerde öğrenim gören öğrencilerin bilgi düzeyindeki farklılıklar araştırılmıştır. Bununla birlikte kredi kartı ve bankamatik kullanım alışkanlıkları, aile eğitim durumu ve cinsiyet gibi değişkenler de analize dahil edilmiştir. Çalışma sonucunda işletme bölümü öğrencilerinin diğer bölümlere göre daha yüksek finansal okuryazarlık seviyesine sahip oldukları belirlenmiştir (Şamiloğlu ve ark., 2016). Öte yandan başka bir çalışmada ise işletme bölümü öğrencilerinin finansal okuryazarlık seviyesinin diğer bölüm öğrencilerine göre daha yüksek olmadığı sonucuna ulaşılmıştır (Altıntaş, 2011). Finans eğitiminin finansal bilgi birikimlerinin düzeyindeki belirleyiciliğine yönelik bir başka araştırmada yine işletme bölümü öğrencilerinin temel düzeyde finans bilgisi edindikleri, bu bilgilerin demografik ve eğitimsel bazı özelliklerden etkilendiği tespit edilmiştir (Contuk, 2018).

Özellikle son dönemlerde finansal okuryazarlık bilgi ve düzeyi ölçümünde iktisadi ve idari bilimler fakültelerinde öğrenim gören öğrencilerin ana kütle olarak seçildiği çalışmalar dikkat çekmektedir. Danışman, Sezer ve Gümüş, İiBF öğrencilerinin finansal kararlara ilişkin etkin fikirlere sahip olabileceklerini düşünerek finansal bilgi düzeyini ölçmeye yönelik bir çalışma gerçekleştirmiş ve öğrencilerin temel düzeyde finansal okuryazar oldukları sonucuna ulaşmıştır. (Danışman, Sezer ve Gümüş, 2016). Selçuk ve Yılmaz, İ̈BF'de okuyan öğrencilerde finansal okuryazarlığı etkileyen faktörleri inceleme amacıyla kişisel özellikler, ailevi özellikler, eğitim düzeyi ve ailenin finansal etkisinin öğrencilerin okuryazarlıkları ile olan ilişkisini araştırmışlardır. Çalışma sonucunda üniversite öğrencilerinin okuryazarlık seviyesinin düşük olduğu ve ortalama bir öğrenci tarafından soruların yarısına bile doğru cevap verilemediği gözlemlenmiştir. Ailenin eğitimi ve babanın çalışıyor olması da finansal okuryazarlık düzeyinde etkili bulunmuş, aile gelirinin etkili olmadığı ve genel not ortalamasının ise anlamlı olmadığı tespit edilmiştir (Selçuk ve Yilmaz, 2015). İIBF ve meslek yüksekokulu öğrencilerine yönelik bir başka çalışmada öğrencilerin kendilerini finansal durumları yönetmede olduklarından daha başarılı algıladıkları tespit edilmiştir. Çalışma sonucunda, gerçek finansal başarıyı elde edebilecekleri programların eğitim kapsamına alınması önerilmiştir (Bayram, 2014). Muhasebe ve finans dersleri hakkında öğrencilerin düşüncelerini belirlemek ve bu derslere yönelik başarılarına bağlı olarak finansal okuryazarlık düzeylerini tespit etmek amacıyla yapılan bir çalışmada öğrencilerin muhasebe ve finans derslerine ilişkin okuryazarlıklarının yeterli olmadığı sonucuna ulaşılmıştır. Ayrıca öğrencilerin 
muhasebe ve finans dersleri hakkındaki görüşlerinde ve finansal okuryazarlık düzeylerinde demografik değişkenlere göre farklılıklar tespit edilmiştir (Demirkol ve Erduru, 2017). Kocabıyık ve Teker’in çalışmasında özellikle İIBF bölümlerinde öğrenim gören öğrencilerin diğer bölümlerdekilere kıyasla finansal okuryazarlık düzeylerinin daha yüksek olduğu ortaya konulmuştur. Ayrıca öğrencilerin okudukları bölüm ve cinsiyet gibi değişkenlerin de finansal okuryazarlığı etkilediği sonucuna ulaşılmıştır (Kocabıyık ve Teker, 2018). Er ve arkadaşları tarafından yapılan çalışmada ise İİBF ve mühendislik fakültesi öğrencilerinin finansal okuryazarlıklar düzeyleri ölçülerek karşılaştırılmıştır. İİBF, eğitim alanı açısından finansal kavramları ve teknikleri tanıma olanağı yüksek olduğu düşünülerek, mühendislik fakültesi ise sayısal analizlerin eğitim içeriğinde daha büyük yer alması sebebi ile seçilmiştir. Eğitim alanları ile finansal okuryazarlık düzeyleri arasındaki ilişkinin anlamlı olduğu sonucuna ulaşılmıştır. (Er ve ark., 2014).

\section{3. Çalışmanın Metodolojisi}

Lojistik regresyon analizi, regresyon analizi mantığında kategorik verilerin analizine olanak sunar. (Kılıç, 2000). Bu nedenle çalışmada iki kategorili bağımlı değişken ve bağımsız değişkenlerin etkilerinin hesaplanabileceği İkili Lojistik Regresyon Analizi yöntemi uygulanmıştır. Bu analiz yönteminin bireylerin hangi kategorinin üyesi olacağına yönelik olasılık değerlerini hesaplamayı sağlaması (Çokluk, Şekercioğlu ve Büyüköztürk, 2018, s.49) çalışmada bu yöntemin seçilmesinde etkili olmuştur. Analiz iki ya da daha fazla gruba ilişkin üyelik tahminini sağladığından hem sınıflandırmayı sağlayacak hem de bağımlı ve bağımsız değişkenler arasındaki ilişkiyi ortaya koyacaktır (Mertler ve Reinhart, 2016, s.308).

Lojistik regresyon, ilgilenilen özelliğin varlığına yönelik olasılığın bir logit dönüşümünü tahmin etmek için oluşturulan matematiksel modelin katsayılarını oluşturur. Bu analizde bağımlı değişkene logit dönüşüm uygulanır (Hair, Black, Babin ve Anderson, 1998, s.341) ve bağımlı değişkenin meydana gelme olasılığının tahmini için standart hatalara ve önem seviyelerine sahip katsayılar oluşturmak amacıyla aşağıdaki denklemi kullanmaktadır:

$$
\operatorname{Logit}(p)=\log \log \left(\frac{1}{1-p}\right)=\beta_{0}+\beta_{1} X_{1}+ß_{2} X_{2}+. . \beta_{k} X_{k}
$$

p: olayın gerçekleşme olasılı̆ğ1

1-p: gerçekleşmeme olasılığ 1

Lojistik regresyonda Odds, bir olayın gerçekleşme olasılığının o olayın gerçekleşmeme olasılığına oranı olarak tanımlanır. Dolayısıyla Odds oranı şu şekilde hesaplanmaktadır:

$$
\text { Odds }=\frac{p}{1-p}
$$

Olasılık değerleri 0 ile 1 arasında yer almaktadır. Ancak Odss değeri bir olayın gerçekleşme ve gerçekleşmeme olasılığının oranı olduğundan 1'den büyük değerler de alabilmektedir. Odds oranı Exp (ß) ile sembolize edilmektedir (Mertler ve Reinhart, 2016, s.310).

Bu bağlamda çalışmaya ilişkin lojistik regresyon modelinde p, öğrencinin finansal okuryazar olma olasılığı tahminidir. Böylece ekonometrik model şu şekilde oluşturulmuştur:

$$
\begin{aligned}
& \text { Logit }(p)=\beta_{0}+\beta_{1}(\text { cinsiyet })+\beta_{2}(\text { bölüm } 1)+\beta_{4}(\text { bölüm } 2)+\beta_{5}(\text { bölüm } 3)+\beta_{5}(\text { sinıf } 1)+\beta_{6}(\text { sinıf } 2) \\
& +\beta_{7}(\text { sinlf } 3)+\beta_{8}(\text { notort } 1)+\beta_{9}(\text { notort } 2)+\beta_{10}(\text { notort } 3)+\beta_{11}(\operatorname{dersdgr} 1) \\
& +\beta_{12}(\text { dersdgr } 2)+\beta_{13}(\text { kendidgr } 1)+\beta_{14}(\text { kendidgr } 2)+\beta_{15}(\text { kendidgr } 3) \\
& \left.+\beta_{16} \text { (kendidgr } 4\right)
\end{aligned}
$$

Çalışmada kullanılan bağımsız değişkenler ile referans gruplarına ilişkin tanımlar Tablo 1'de gösterilmiştir. 


\begin{tabular}{|c|c|}
\hline $\mathrm{P}$ & Katılımcı öğrencinin finansal okuryazar olma olasılığ \\
\hline Cinsiyet & Eğer katılımc1 "erkek" ise 1, değil ise 0 \\
\hline Kadın & Referans grup \\
\hline Bölüm1 & Öğrencinin programı "Uluslararası Ticaret" ise 1 , değilse 0 \\
\hline Bölüm2 & Öğrencinin programı "Ekonomi ve Finans" ise 1, değilse 0 \\
\hline Bölüm3 & Öğrencinin programı" İnsan Kaynakları Yönetimi” ise 1 , değilse 0 \\
\hline İşletme & Referans grup \\
\hline Sinif1 & Öğrenci “2.sınıfta” öğrenim görmekte ise 1 , değilse 0 \\
\hline Sinif2 & Öğrenci “3.sınıfta” öğrenim görmekte ise 1 , değilse 0 \\
\hline Sinif3 & Öğrenci “4.sınıfta” öğrenim görmekte ise 1 , değilse 0 \\
\hline 1.sinif & Referans grubu \\
\hline Notort1 & Öğrencinin not ortalamas " 2,00 ve 2,49 aras1" ise 1 , değilse 0 \\
\hline Notort2 & Öğrencinin not ortalamas1 " 2,50 ve 2,99 arası" ise 1 , değilse 0 \\
\hline Notort3 & Öğrencinin not ortalaması " 3 'ten fazla" ise 1 , değilse 0 \\
\hline 2'den az & Referans grubu \\
\hline Dersdgr1 & Öğrencinin finans eğitiminin etkisine yönelik düşüncesi "bilmiyorum" ise 1 , değilse 0 \\
\hline Dersdgr2 & Öğrencinin finans eğitiminin etkisine yönelik düşüncesi “hayır” ise 1 , değilse 0 \\
\hline Evet & Referans grubu \\
\hline Kendidgr1 & Öğrencinin kendi finansal okuryazarlığını gördüğü düzey “düşük” ise 1 , değilse 0 \\
\hline Kendidgr2 & Öğrencinin kendi finansal okuryazarlığını gördüğü düzey “orta” ise 1 , değilse 0 \\
\hline Kendidgr3 & Öğrencinin kendi finansal okuryazarlığını gördüğü düzey “iyi” ise 1, değilse 0 \\
\hline Kendidgr4 & Öğrencinin kendi finansal okuryazarlığını gördüğ̈ düzey “çok iyi” ise 1 , değilse 0 \\
\hline Çok düşük & Referans grubu \\
\hline
\end{tabular}

\subsection{Veri Toplama Yöntemi ve Örneklem}

$\mathrm{Bu}$ çalışma, üniversitede verilen muhasebe ve finans eğitiminin, öğrencilerin finansal okuryazarlık durumları üzerindeki etkisini ölçmeyi amaçlamaktadır. Diğer fakültelere kıyasla İ.İ.B.F. bölümlerinde muhasebe, finans içerikli dersler yoğunluk gösterdiğinden bu fakülte tercih edilmiştir. Bu kapsamda Alanya Alaaddin Keykubat Üniversitesi İ.İ.B.F. öğrencilerine 34 soruluk bir anket düzenlenmiştir. Anket soruları Bayram’ın (Bayram, 2014) konuya ilişkin çalışmasından ve finansal okuryazarlığı̈ ölçme anketinden (OECD, 2011) elde edilmiş ve Kaya’nın çalışmasından seçilmiştir (Kaya, 2019).

Anket toplama işlemi online olarak gerçekleştirilmiş, gönüllülük esaslı kolayda örnekleme metodu uygulanmıştır. Elde edilen veriler ile ilk olarak betimleyici istatistikleri gözlemlemek amacıyla frekans dağılımları incelenmiştir. Ankette yer alan ilk dört soru cinsiyet, bölüm, sınıf, genel not ortalaması gibi bilgilere ilişkin sorulardır. Sonraki iki soruda öğrencilerden, kendi finansal okuryazarlıklarına ve aldıkları finans eğitimine ilişkin öznel değerlendirmeler alınmıştır. Sonraki dokuz soru finansal bilgi ve düzeylerini ölçmeye yönelik hesaplama sorularıdır. Son kısımda ise 19 adet finansal kavram verilmiş ve öğrencilerden bu kavramlara ilişkin bilgi düzeylerini Likert ölçek tipine uygun şekilde cevaplamaları istenmiştir. Araştırmada finansal okuryazarlık düzeylerinin ölçülmesine ve finansal kavram bilgisine yönelik değerlendirmelere ilişkin güvenilirlik analizi gerçekleştirilerek Cronbach Alpha değeri yaklaşık \%92 olarak bulunmuştur.

2019-2020 öğretim yılı itibari ile Alanya Alaaddin Keykubat Üniversitesi İktisadi ve İdari Bilimler Fakültesi’nde 2014 öğrenci öğrenim görmektedir. İstatistiksel analize göre bu sayıda bir öğrenci topluluğu için 322 anket yeterli görülmektedir (Sekaran ve Bougie, 2016). Çalışmamızda toplam 325 anket analize dahil edilmiştir.

Çalışmada cinsiyet, bölüm, sınıf, genel not ortalaması, öğrencilerin üniversitedeki finansal eğitime yönelik dersler hakkındaki görüşleri ve kendi finansal okuryazarlığına ilişkin değerlendirmeler bağımsız değişkenler olarak seçilmiştir. Bağımlı değişken 0=finansal okuryazar değil, 1=finansal okuryazar olmak üzere sınıflandırılmıştır. Bu analiz öğrencilerin, finansal okuryazar değil ve finansal okuryazar olarak sınıflandırılmış gruplara üyeliklerini tahmin etmede bağımsız değişkenlerin etkisini ortaya koyacaktır. Seçilen bağımsız değişkenlerin tümü kategorik şekilde tanımlanmış, bağımlı değişken dahil tüm değişkenlerde ilk düzeyler referans sınıfı olarak seçilmiştir. 
Finansal okuryazarlığa ve ölçümüne yönelik literatür çalışmalarının \%90’ında araştırmaya konu olan bireylerin finansal okuryazar olduklarına ilişkin standart bir gösterge elde edilememiş, geri kalan araştırmalarda ise finansal okuryazarlığın ölçülmesi ve yorumlanmasında bir eşik değer kullanılmıştır (Huston, 2010, s.303). Çalışmada öğrencilerin finansal okuryazar olup olmamaları bir eşik değer yardımıyla belirlenmiş, finansal bilgiyi ölçen sorulara verilen doğru cevap skorunun ortanca değerinin eşik değer olarak belirlenmesi uygun görülmüştür (Volpe, ve ark., 1996; Chen ve Volpe, 1998; Volpe, Kotel ve Chen, 2002; Beal ve Delpachitra, 2003; Suwanaphan, 2013). Buna göre ortanca skorundan (\%55.55) daha yüksek okuryazarlık skoruna sahip öğrenciler 1 ile kodlanmıştır. 1-p, öğrencinin finansal okuryazarlık düzeyinin düşük olması durumudur ve medyan skoruna (\%55.55) eşit veya daha düşük okuryazarlık skoruna sahip öğrenciler 0 ile kodlanmıştır.

\section{4. Çalışmadan Elde Edilen Bulgular}

Tablo 2'de değişkenlere ilişkin frekans dağılımları ve yüzde dağılımlar verilmiştir. Tablo 2'de görüldüğü üzere ankete katılan öğrencilerin \% 54,8'lik kısmı erkek öğrencilerdir. Bölümlere ilişkin dağılım incelendiğinde ankete katılanların yarıdan fazlası işletme bölümü öğrencisi olup, en az katılım sağlayan bölüm \% 2,8 oran ile ekonomi ve finans bölümü olmuştur. Öğrencilerin not ortalamasının çoğunlukla 2,00 ile 2,99 arasında olduğu görülmektedir. Fakültede verilen finans derslerine ilişkin öğrencilerin görüşleri \% 39,7 oranında etkili olduğu şeklinde olmakla birlikte, \% 34,5’lik bir kısmın bu soruya çekimser kaldığı görülmektedir. Katılımcıların büyük bir kısmı kendi finansal okuryazarlık düzeyini orta derece olarak değerlendirmiş, yaklaşık \%33'lük bir kısım orta seviyenin altında finansal okuryazarlık düzeyine sahip olduğunu belirtmiştir. 70 katılımcının ise kendi finansal okuryazarlık düzeyini yüksek (iyi ve çok iyi) olarak değerlendirdiği görülmektedir. 255 kişi finansal okuryazarlık düzeyini iyi olarak tanımlamaya yeterli görmemiş, hesaplamalar sonucu 239 katılımcının finansal okuryazar olma düzeyinde yeterli olmadığı tespit edilmiştir. Bu sebeple öğrencilerin önemli bir kısmının kendi finansal okuryazarlıklarına ilişkin değerlendirmelerinde fazla iyimser ya da kötümser değil, gerçekçi davrandıkları söylenebilmektedir.

\begin{tabular}{|c|c|c|c|}
\hline Bağımsız Değişkenler & Bağımsız Değişken Kategorileri & Frekans Dağılımı & Yüzde Dağılım \\
\hline \multirow[t]{2}{*}{ Cinsiyet } & Kadın & 147 & 45,2 \\
\hline & Erkek & 178 & 54,8 \\
\hline \multirow[t]{4}{*}{ Bolum } & İşletme & 177 & 54,5 \\
\hline & Uluslararası Ticaret & 44 & 13,5 \\
\hline & Ekonomi ve Finans & 9 & 2,8 \\
\hline & İnsan Kaynakları & 95 & 29,2 \\
\hline \multirow[t]{4}{*}{ Sinif } & 1.Sinif & 60 & 18,5 \\
\hline & 2.Sinif & 12 & 3,7 \\
\hline & 3.Sinif & 103 & 31,7 \\
\hline & 4.Sinif & 150 & 46,2 \\
\hline \multirow[t]{4}{*}{ Notort } & 2,00 'den az & 60 & 18,5 \\
\hline & 2,00 ve 2,49 aras 1 & 123 & 37,8 \\
\hline & 2,50 ve 2,99 aras 1 & 84 & 25,8 \\
\hline & 3.00'ten fazla & 58 & 17,8 \\
\hline \multirow[t]{3}{*}{ Dersdgr } & Evet & 129 & 39,7 \\
\hline & Bilmiyorum & 112 & 34,5 \\
\hline & Hayır & 84 & 25,8 \\
\hline \multirow[t]{5}{*}{ Kendidgr } & Çok Düşük & 33 & 10,2 \\
\hline & Düşük & 75 & 23,1 \\
\hline & Orta & 147 & 45,2 \\
\hline & İyi & 48 & 14,8 \\
\hline & Çok İyi & 22 & 6,8 \\
\hline
\end{tabular}


Lojistik regresyon analizi uygulandığında ilk adımda yalnızca sabit değerin yer aldığı başlangıç modelinde yer alan ilk hata ki kare p değeri 0,025 olarak hesaplanmıştır. Bu değer başlangıç modelinde yer almayan bağımsız değişkenlerin katsayılarındaki değişimin anlamlı derecede sıfırdan farklı olduğunu ifade eder. Başka bir deyişle analizde belirtilen bir ya da daha fazla bağımsız değişkenin modele eklenmesinin modeli açıklama gücünü arttıracağını belirtir. Ayrıca model tüm katılımcıların \%73,8'lik kısmını doğru sınıflandırmaktadır. Sonraki adımda bağımsız değişkenler modele dahil edilerek ölçüm gerçekleştirilmiştir. Tablo 3’te değişkenlerin modele dahil edilmesi ile model katsayılarına yönelik Omnibus testi sonuçları sunulmaktadır. Burada Ki-kare istatistik değerinin anlamlılık düzeyi her bir adım, blok ve model için ayrıca belirtilir. Açıklayıcı değişkenlerin yer almadığı model ile bunların modele eklenmesi sonucu oluşan model arasındaki fark 0,016 olarak hesaplanmış ve istatistiki açıdan anlamlı bulunmuştur $(0,016<0,05)$. Buna göre modelin açıklayıcı gücü bulunmaktadır ve bağımsız değişkenlerin modele alınması değişkenler arasındaki ilişkiyi geliştirmek için uygun olacaktır.

Tablo 3: Model Katsayılarına İlişkin Omnibus Testi

\begin{tabular}{|c|c|c|c|c|}
\hline \multicolumn{5}{|c|}{ Omnibus Tests of Model Coefficients } \\
\hline \multirow{3}{*}{ Step 1 } & Chi-square & df & Sig. \\
\cline { 2 - 6 } & Step & 30,477 & 16 &, 016 \\
\cline { 2 - 6 } & Mock & 30,477 & 16 &, 016 \\
\hline
\end{tabular}

Tablo 4.4'te yer alan Cox \& Snell R2, Nagelkerke $R^{2}$ değerleri bağımsız değişkenlerin, bağımlı değişkende meydana gelecek bir değişimin ne kadarlık kısmını açıklayabileceğine ilişkin bilgi vermektedir. Buna göre modeldeki bağımsız değişkenler Nagelkerke $R^{2}$ değerine göre modelin bağımlı değişkendeki varyansın yaklaşık \%13’lük kısmını açıklayabilmektedir.

\begin{tabular}{|l|c|c|c|}
\hline \multicolumn{4}{|l|}{ Tablo 4: Model Özet Tablosu } \\
\hline Step & -2 Log likelihood & Cox \& Snell R Square & Nagelkerke R Square \\
\hline 1 & $345,113^{\mathrm{a}}$ &, 090 &, 131 \\
\hline
\end{tabular}

Ki-kare uyum iyiliği olarak da anılan Hosmer ve Lemeshow testi modelin bütün olarak uyumunu değerlendirir. Tablo 5’te teste ilişkin p değerinin 0,05’ten büyük olması gözlenen ile model tarafından tahmin edilen değerler arasında anlamlı bir fark olmadığını ifade eder (Garson, 2020). Buna göre 0,749 ile model aracılı̆̆ıla tahmin edilen değerler ile gözlenen değerler arasında anlamlı fark olmadığı görülmektedir.

\begin{tabular}{|l|c|c|c|}
\hline \multicolumn{4}{|l|}{ Tablo 5: Hosmer ve Lemeshow Testi } \\
\hline Step & Chi-square & df & Sig. \\
\hline 1 & 5,080 & 8 &, 749 \\
\hline
\end{tabular}

Modelde bağımlı değişken finansal okuryazarlık durumu, bağımsız değişkenler ise cinsiyet, bölüm, sınıf, not ortalaması, kendi finansal okuryazarlığına ilişkin değerlendirme ve derslerin etkisine ilişkin değerlendirme olarak belirtilmiştir. Lojistik regresyonda, her bir bağımsız değişkenin $\beta$ katsayısı, her bir kategorinin referans kategorisine görece bağımlı değişken varyansına kısmi etkisini ifade etmektedir. Lojistik regresyon modeli analiz sonuçları Tablo 6'da gösterilmiştir.

Analiz sonuçlarında "Sınıf1” (2,771) katsayısı pozitif yönlü ve 0,01 düzeyinde anlamlı bulunmuş ve Odds oranı (Exp ß) 15,973 olarak saptanmıştır. Buna göre ikinci sınıf öğrencilerinin finansal okuryazar olma olasılığı birinci sınıf öğrencilerine göre 15,973 kat daha fazladır. Ayrıca "Sınıf3” değişkeni $(1,151)$ katsayısı pozitif yönlü ve 0,05 düzeyinde istatistiki olarak anlamlı bulunmuş, Odds oranı 3,16 olarak tespit edilmiştir. Son sınıf öğrencilerinin finansal okuryazar olma olasılıklarının dördüncü sınıf öğrencilerine kıyasla 3,16 kat daha fazla olduğunu söylemek mümkündür.

Not ortalaması 2.00‘den düşük olan öğrencilere kıyasla, not ortalaması 2,50 ve 3,00 arası olan öğrencilerin başarılı olması daha olası bir durumdur. Ancak analiz sonuçlarında "Notort2" (-0,883) katsayısı negatif yönlü ve 0,1 düzeyinde anlamlı bulunmuş ve Odds oranı (Exp ß) 0,414 olarak saptanmıştır. Buna göre not ortalaması 2,50 ile 2,99 olan öğrencilerin finansal okuryazar olma olasılığı, not ortalaması 2'den az olan öğrencilere kıyasla 0,414 kat daha azdır. Başka bir deyişle not ortalaması bu değişkene ilişkin referans grubundaki öğrencilere kıyasla daha yüksek olan öğrencilerin finansal okuryazar olma olasılığı düşmektedir. Not ortalaması 2,00'den az olan öğrenciler 2,50 ile 3,00 arası olan öğrencilere kıyasla daha fazla 
finansal bilgiye sahiptir. Dolayısıyla not ortalaması 2,50 ile 2,99 arası olan bireylerin ders notlarındaki başarının finansal içerikli derslerden farklı olduğu düşünülebilir.

\begin{tabular}{|l|c|c|c|c|c|c|}
\hline Tablo 6: Lojistik Regresyon Modeli Analiz Sonuçlar1 \\
\hline Step 1 & B & S.E. & Wald & df & Sig. & Exp (B) \\
\hline Cinsiyet(1) & $-0,024$ & 0,324 & 0,006 & 1 & 0,94 & 0,976 \\
\hline Bolum & & & 3,077 & 3 & 0,38 & \\
\hline Bolum(1) & 0,378 & 0,466 & 0,658 & 1 & 0,417 & 1,459 \\
\hline Bolum(2) & 0,216 & 0,886 & 0,059 & 1 & 0,807 & 1,241 \\
\hline Bolum(3) & $-0,447$ & 0,394 & 1,29 & 1 & 0,256 & 0,639 \\
\hline Sinıf & & & 12,821 & 3 & 0,005 & \\
\hline Sinıf(1) & 2,771 & 0,799 & 12,024 & 1 & 0,001 & 15,973 \\
\hline Sinif(2) & 0,812 & 0,555 & 2,135 & 1 & 0,144 & 2,251 \\
\hline Sinif(3) & 1,151 & 0,567 & 4,114 & 1 & 0,043 & 3,16 \\
\hline Notort & & & 3,848 & 3 & 0,278 & \\
\hline Notort(1) & $-0,47$ & 0,391 & 1,447 & 1 & 0,229 & 0,625 \\
\hline Notort(2) & $-0,883$ & 0,45 & 3,843 & 1 & 0,05 & 0,414 \\
\hline Notort(3) & $-0,529$ & 0,519 & 1,039 & 1 & 0,308 & 0,589 \\
\hline Kendidgr & & & 7,98 & 4 & 0,092 & \\
\hline Kendidgr(1) & 0,501 & 0,56 & 0,798 & 1 & 0,372 & 1,65 \\
\hline Kendidgr(2) & 0,226 & 0,543 & 0,173 & 1 & 0,677 & 1,254 \\
\hline Kendidgr(3) & 1,182 & 0,643 & 3,379 & 1 & 0,066 & 3,261 \\
\hline Kendidgr(4) & 1,338 & 0,724 & 3,415 & 1 & 0,065 & 3,813 \\
\hline Dersdgr & & & 1,457 & 2 & 0,483 & \\
\hline Dersdgr(1) & 0,442 & 0,401 & 1,213 & 1 & 0,271 & 1,555 \\
\hline Dersdgr(2) & 0,462 & 0,433 & 1,143 & 1 & 0,285 & 1,588 \\
\hline Constant & $-2,214$ & 0,789 & 7,865 & 1 & 0,005 & 0,109 \\
\hline
\end{tabular}

Analiz sonuçlarında "Kendidgr3" (1,182) katsayısı pozitif yönlü ve 0,1 düzeyinde anlamlı bulunmuş ve Odds oranı (Exp ß) 3,261 olarak saptanmıştır. Buna göre kendi finansal okuryazarlık düzeyini ‘'̇yi’ olarak tanımlayan öğrencilerin finansal okuryazar olma olasılığ ' 'Çok Düşük' olarak tanımlayan öğrencilere göre 3,261 kat daha fazladır. Aynı şekilde "Kendidgr4” değişkeni $(1,338)$ katsayısı pozitif yönlü ve 0,1 düzeyinde istatistiki olarak anlamlı bulunmuş, Odds oranı 3,813 olarak tespit edilmiştir. Kendi finansal okuryazarlık düzeyini ‘Çok İyi’ olarak tanımlayan öğrencilerin finansal okuryazar olma olasılığ ‘Çok Düşük’ olarak tanımlayan öğrencilere göre 3,813 kat daha fazladır. Frekans analizlerinde öğrencilerin kendi finansal okuryazarlık düzeylerine ilişkin değerlendirmelerindeki tutumları ile bu istatistiki anlamlılığın örtüştüğü görülmektedir.

\section{Sonuç}

Bu çalışmada Alanya Alaaddin Keykubat Üniversitesi İktisadi ve İdari Bilimler Fakültesi’nde okuyan öğrencilerin finansal dersler, bölüm, sınıf gibi farklı kategorik değişkenlerin finansal okuryazarlık düzeyine etkisi incelenmiştir. Öğrencilerin temel finansal okuryazarlık düzeyleri \%55,55 olarak hesaplanmıştır. Başka bir deyişle fakültede okuyan öğrencilerin finansal okuryazarlık sorularına verilen doğru cevap ortalaması \% 55,55 olarak bulunmuştur. Bu ortalamaya göre öğrenciler iki gruba ayrılmış ve finansal okuryazar olarak tanımlanabilecek öğrencilerin fakülte öğrencilerine oranı \%26 olarak hesaplanmıştır.

Finansal okuryazar olma olasılığının tahmininde cinsiyet değişkeni istatistiki olarak anlamlı bulunmamıştır. Üniversite öğrencilerine yönelik yapılan finansal okuryazarlık çalışmalarına ilişkin bulgularda cinsiyet değişkeninin etkili olduğu öne sürülen çalışmaların aksine, cinsiyet ile finansal okuryazarlık bilgi veya düzeyi arasında herhangi bir ilişki bulunmadığ sonucu benzer çalışmalarla örtüşmektedir (Adeleke, 2013; Jorgensen \& Savla, 2010; Rosacker \& Rosacker, 2016; Razafimahasolo vd., 2016; Barış, 2016; Ludlum ve ark., 2012).

Birinci sınıfı başarı ile tamamlamış olan öğrencilerin finansal okuryazar olma olasılıklarının önemli derecede artması sonucu, finansal bilgi düzeyinin eğitime ilk başlanılan yılın bitirilmesinin ardından artış gösterdiği bulgularına ulaşan çalışmalar ile örtüşmektedir (Jorgensen \& Savla, 2010; Gümüş \& Pailer, 2019; Tuna \& Ulu, 2016). Fakültede tüm bölümlerin 
birinci sınıf ders kataloğunda altı saatlik zorunlu temel muhasebe dersi bulunduğu görülmüştür. Bu durum öğrencilerin özellikle ilk sene almış oldukları temel finansal eğitimin finansal okuryazar olma olasılığını önemli derecede arttırdığ1 anlamına gelmektedir. Öte yandan öğrencilerin farklı bölümlerde öğrenim görmeleri, kimi çalışmaların aksine ileri finansal okuryazar olma olasılığını etkilememektedir. Öğrencilerin referans grubu olarak alınan işletme bölümünde öğrenim görmelerinin, diğer bölümlere kıyasla finansal okuryazarlık düzeyini etkilemediği sonucuna ulaşılmıştır. Bölümlere ilişkin ders müfredatında zorunlu finansal ders saatleri farklı olsa da bu farklılık finansal okuryazarlık düzeyinde etkili olmamıştır.

Not ortalamaları düşük olan referans grubu öğrencilerine kıyasla daha belirli bir aralıkta ve daha yüksek ders notları olan öğrencilerin finansal okuryazar olma olasılıklarının azaldığı sonucuna da ulaşı1mıştır. Bu durum fakültedeki 2,50 ve 2,99 not ortalamasına ulaşmış öğrencilerin daha düşük başarıdaki öğrencilere kıyasla daha yüksek not ortalamasına sahip olmalarını diğer dersler aracılığıyla sağlamış oldukları anlamına gelmektedir. Başka bir deyişle genel anlamda başarısız öğrencilerden daha başarılı olma sebepleri finansal içerikli dersler dışındaki derslerdir.

Öğrencilerin, fakültede verilen derslerin etkili olduğu düşüncesinde ya da aksi düşüncede olmalarının, finansal okuryazar olma durumunu etkilemediği belirlenmiştir. Bununla birlikte kendini finansal okuryazar olarak değerlendiren öğrencilerin, bu görüşlerinin finansal okuryazar olma olasılıklarını etkilediği sonucuna da ulaşılmıştır.

\section{Son Notlar}

Çalışma, genel anlamda fakülte öğrencilerinin finansal okuryazarlık seviyesinin düşük olduğunu belirlemiştir. Bu finansal okuryazarlık düzeyini yükseltmek için analiz sonucunda etkin bulunan bağımsız değişkenlere ilişkin detaylar kapsamında iyileştirme ve düzenlemeler yapılması önerilebilir. Zorunlu temel finans derslerinin bulunduğu birinci sınıfı başarıyla tamamlamış olmanın, finansal okuryazar olma olasılığında etkin olduğu görülmektedir. Bu bağlamda birinci sınıfta verilen finansal içerikli zorunlu derslerin teorik iletimi ve uygulanma şeklinin incelenmesi, diğer finansal içerikli derslerin bu şekilde düzenlenmesi faydalı olabilecektir. Bölümlerde zorunlu finans ders saatlerinin farklı olduğu ve bazı bölümlerin daha fazla ders saati olmasına rağmen bölümlere göre finansal okuryazarlık düzeyinde farklılık olmadı̆̆ı tespit edilmiştir. $\mathrm{Bu}$ sebeple görece fazla saatte finansal içerikli ders alan bölümlerde daha fazla okuryazar olma olasılıklarında artış görülmemesi, içeriklerinin gözden geçirilmesi ve daha etkin hale getirilmesi gerektiğini gösterir. Bundan sonra yapılacak çalışmalarda farklı üniversitelerin İ.İ.B.F. bölümleri ile veya farklı fakülte öğrencilerinin finansal okuryazarlık seviyeleri karşılaştırmalı olarak incelenebilir.

Hakem Değerlendirmesi: Dıș bağımsız.

Çıkar Çatışması: Yazarlar çıkar çatışması bildirmemiştir.

Finansal Destek: Yazarlar bu çalışma için finansal destek almadığını beyan etmiştir.

Peer-review: Externally peer-reviewed.

Conflict of Interest: The authors have no conflict of interest to declare.

Grant Support: The authors declared that this study has received no financial support.

\section{Kaynaklar}

Adeleke, T. (2013). The effects of gender and gender role on the financial literacy of college students. Wilmington, North Carolina: Oklahoma State University

Agarwal, S., Driscoll, J. C., Gabaix, X. ve Laibson, D. (2009). The age of reason: Financial decisions over the lifecycle. Brookings Papers on Economic Activity, (2), 51-117.

Alba, Joseph V. \& Hutchinson J. W. (1987). Dimensions of consumer expertise. Journal of Consumer Research, 13(4), 411-454.

Alkaya, A. \& Yağlı, İ. (2015). Finansal okuryazarlık-finansal bilgi, davranış ve tutum: Nevşehir Hacı Bektaş Veli Üniversitesi İIBF öğrencileri üzerine bir uygulama. Journal of International Social Research, 8(40), 585-599. 
Altintas, K. M. (2011). The dynamics of financial literacy within the framework of personal finance: An analysis among Turkish university students. African Journal of Business Management 5(26), 10483-10491.

Atkinson, A. \& Flore-Anne, M. (2012). Measuring financial literacy: Results.

Barış, S. (2016). finansal okuryazarlık ve bütçeleme davranışı: Üniversite öğrencileri üzerine bir araştırma. TESAM Akademi Dergisi 3(2), 13-38.

Barmakı, N. \& Şener, A. (2017). Üniversite öğrencilerinin finansal okuryazarlik düzeyleri. Journal of Current Researches on Social Sciences 7(3), 67-88.

Bayram, S. S. (2014). Finansal Okuryazarlık Ve Para Yönetimi Davranışları: Anadolu Üniversitesi Öğrencileri Üzerine Uygulama. Business \& Management Studies: An International Journal 2(2), 105-135.

Beal, D. J. \& Delpachitra, S. B. (2003). Financial Literacy Among Australian University Students. Economic Papers, 65-78.

Borden, L. M., Sun-A Lee, J. S. \& Collins, D. (2008). Changing college students' financial knowledge, attitudes, and behavior through seminar participation. Journal of Family and Economic, 29, 23-40.

Bruin, W. B., Vanderklaauw, W., Downs, J. S., Fischhoff, B. \& Topa, G. (2010). Expectations of inflation: The role of demographic variables, expectation formation, and financial literacy. Journal of Consumer Affairs 44(2), 381-402.

Chen, H. \& Volpe, R. P. (1998). An analysis of personal financial literacy among college students. Financial Services Review, (7)2, 107-128.

Chen, H. \& Volpe, R. P. (2002). Gender Differences İn Personal Financial Literacy Among College Students. Financial Services Review 11(3), 289-307.

Coleman, S. (2003). Women And Risk: An Analysis Of Attitudes And İnvestment Behavior. Academy Of Accounting And Financial Studies Journal, 7(2) 99.

Contuk, F. Y. (2018). Üniversite öğrencilerinin finansal okuryazarlık durumunu etkileyen faktörler üzerine bir araştırma: Muğla Sitkı Koçman Üniversitesi örneği. Muhasebe ve Finansman Dergisi, 113-136.

Coşkun, S. (2016). Üniversite öğrencilerinin finansal davranış ve tutumlarının belirlenmesi: Finansal okuryazarlık algıları üzerine bir araştırma. Itobiad: Journal of the Human \& Social Science Researches, 5(7), 2247-2258.

Cude, B. J., Lawrence, F. C., Lyons, A. C., Metzger, K., LeJeune, E., Marks, L. \& Machtmes, K. (2006). College students and financial literacy: What they know and what we need to learn. eastern family. Economics and Resource Management Association, $102-109$.

Cull, M., \& Whitton, D. (2011). University students' financial literacy levels: Obstacles and aids. The Economic and Labour Relations Review, 99-114.

Çam, A. V. \& Barut, A. (2015). Finansal okuryazarlık düzeyi ve davranışları: Gümüşhane Üniversitesi önlisans öğrencileri üzerine bir araştırma. Global Journal of Economics and Business Studies, 4(7), 63-72.

Çinko, M., Avc1, E., Ergun, S. \& Tekçe, M. (2017). Financial literature levels of university students: An example of Marmara University. Marmara Business Review 2(1), 25-50.

Çokluk, Ö., Şekercioğlu, G. \& Büyüköztürk, Ş. (2018). Sosyal bilimler için çok değişkenli istatistik: SPSS ve LISREL uygulamaları. Ankara: Pegem Akademi.

Danes, S. \& Hira, T. (1987). Money management knowledge of college students. Journal of Student Financial Aid, (17)1, 4-16.

Danışman, E., Sezer, D. \& Gümüş, U. T. (2016). Finansal okuryazarlık düzeyinin belirlenmesi: Üniversite öğrencileri üzerine bir araştırma. Kara Harp Okulu Bilim Dergisi, 26(2), 1-37.

Demirkol, F. \& Erduru, İ. (2017). Üniversite öğrencilerinin finansal okuryazarlık düzeylerinin tespitine yönelik bir araştırma: Harran Üniversitesi örneği. İşletme ve İktisat Çalışmaları Dergisi, 12-26.

Dvorak, T. \& Hanley, H. (2010). Financial literacy and the design of retirement plans. The Journal Of Socio-Economics, 39(6), 645-652.

Elmas, B. \& Yılmaz, H. (2016). Finansal okuryazarlık: Ağrı İbrahim Çeçen Üniversitesi İktisadi Ve İdari Bilimler Fakültesi öğrencileri üzerine bir çalışma. Ağrı İbrahim Çeçen Üniversitesi Sosyal Bilimler Enstitüsü Dergisi, 2(1), 1. 
Er, F., Temizel, F., Özdemir, A. \& Sönmez, H. (2014). Lisans eğitim programlarının finansal okuryazarlık düzeyine etkisinin tespiti. Anadolu Üniversitesi Sosyal Bilimler Dergisi, 113-125.

Ergün, B., Şahin, A. \& Ergin, E. (2014). Finansal okuryazarlık: İşletme bölümü öğrencileri üzerine bir çalışma. Uluslararası Sosyal Araştırmalar Dergisi, 847-867.

Fernandes, D., Jr., J. G. \& Netemeyer, R. G. (2014). Financial literacy, financial education, and downstream financial behaviors. Management Science. 60(8), 1861-1883.

Furtuna, F. (2007). College students' personal financial literacy: Economic impact and public policy implications. Undergraduate Economic Review, 4(1),1.

Garson, G. D. (2020). Logistic regression. Erişim adresi: https://faculty.chass.ncsu.edu/garson/PA765/logistic.htm

Gümüş, U. T. \& Pailer, M. K. (2019). Öğrencilerin finans dersi alma durumunun finansal okur yazarlık seviyesine etkisi: Bir nazilli örneği. OPUS Uluslararası Toplum Araştırmaları Dergisi, 11, 1496-1516.

Güvenç, H. (2017). Öğretim programlarımızda finansal okuryazarlık. Elementary Education Online, 16(3), 935-948.

Hair, J. F., Black, W. C., Babin, B. J. \& Anderson, R. E. (1998). Multivariate data analysis. Pearson.

Hung, A. A., Parker, A. M. \& Yoong, J. (2009). Defining and measuring financial literacy. RAND Working Paper Series WR-708.

Huston, S. J. (2010). Measuring financial literacy. Journal of Consumer, 44(2), 296-316.

Jorgensen, B. L., \& Savla, J. (2010). Financial literacy of young adults: The importance of parental socialization. Family Relations, 59(4), $465-478$.

Kaya, H. (2019). Finansal okuryazarlık ve İ̈BF'de verilen muhasebe ve finansman derslerinin finansal okuryazarlık üzerine etkileri: Cumhuriyet Üniversitesi İİBF öğrencileri üzerinde bir araştırma. Sivas Cumhuriyet Üniversitesi Sosyal Bilimler Enstitüsü.

Kılıç, S. (2000). Lojistik regresyon analizi ve pazarlama araştırmalarında bir uygulama. İstanbul Teknik Üniversitesi Fen Bilimleri Enstitüsü.

Kılıç, Y., Ata, H. A. \& Seyrek, İ. H. (2015). Finansal okuryazarlık: Üniversite öğrencilerine yönelik bir araştırma. Muhasebe ve Finansman Dergisi, 129-150.

Kocabıyık, T. \& Teker, T. (2018). Finansal okuryazarlık: Süleyman Demirel Üniversitesi öğrencileri üzerine bir araştırma. Stratejik ve Sosyal Araştırmalar Dergisi, 2(2), 117-144.

Kozina, F. L. \& Ponikvar, N. (2015). Financial literacy of first-year university students: The role of education. International Journal of Management, Knowledge and Learning, 4(2), 241-255.

Ludlum, M., Tilker, K., Ritter, D., Cowart, T. W., \& Xu, W. (2012). Financial literacy and credit cards: A multicampus survey. Accounting, Finance \& Business Law Faculty Publications and Presentations, (2), 25-33.

Luksander, A., Béres, D., Huzdik, K. \& Német, E. (2014). Analysis of the factors that influence the financial literacy of young people studying in higher education. Public Finance Quarterly, (2), 220-241.

Lusardi, A. \& Mitchelli, O. S. (2007). Financial literacy and retirement preparedness: Evidence and implications for financial education. Business Economics 42, 35-44.

Lusardi, A. \& Tufano, P. (2015). Debt literacy, financial experiences, and overindebtedness. Journal of Pension Economics \& Finance, 14(4), 332-368.

Mandell, L. (2006). Financial literacy: If it's so 1mportant, why 1sn't it 1mproving? Networks Financial Institute Policy Brief, 1-11.

Mandell, L. (2008). The financial literacy of young American adults. Washington: The Jump\$tart Coalition for Personal Financial Literacy.

Markovich, C. A. \& DeVaney, S. A. (1997). College seniors' personal finance knowledge and practices. Journal of Family and Consumer Sciences, 89(3), 61.

Mason, C. L. \& Wilson, R. M. (2000). Conceptualising financial literacy. Loughborough: Business School, Loughborough University. 
Mertler, C. A. \& Reinhart, R. V. (2016). Advanced and multivariate statistical methods: Practical application and interpretation 6.th Edition. New York and London: Taylor \& Francis.

Mitchell, O. S., Lusardi, A \& Curto, V. (2009). Financial literacy among the young: evidence and implications for consumer policy. Pension Research Council WP 9, 1-33.

Nidar, S. R. \& Bestari, S. (2012). Personal financial literacy among university students (case study at padjadjaran university students, Bandung, Indonesia). World Journal of Social Sciences, 2(4), 162-171.

Noctor, M., Stoney, S. \& Stradling, R. (1992). Financial literacy: a discussion of concepts and competences of financial literacy and opportunities for its introduction into young people's learning. London, U.K.: NFER.

OECD. (2005). Recommendation on principles and good practices for financial education and awareness.

OECD. (2011). Measuring Financial Literacy: Core questionnaire in measuring financial literacy: Questionnaire and guidance notes for conducting an internationally comparable survey of financial literacy. Paris: INFE.

OECD. (2020). Financial education and youth. Erişim adresi: https://www.oecd.org/finance/financial-education-and-youth.htm.

Peng, T.-C. M., Bartholomae, S., Fox, J. J ve Cravener, G. (2007). The impact of personal finance education delivered in high school and college courses. J Fam Econ, 265-284.

Razafimahasolo, M., Borromeo, R., Sausa, L., Carpizo, R., \& Sabado, J. (2016). Impact of financial literacy on level of stress And academic achievement among college students. AUP Research Journal, 9(12), 22-36.

Remund, D. L. (2010). Financial literacy explicated: The case for a clearer definition in an increasingly complex economy. Journal of Consumer Affairs, 44(2), 276-295.

Robb, C. A. (2011). Financial knowledge and credit card behavior of college students. Journal of Family and Economic Issues, 32(4), 690-698.

Robb, C. A. \& Sharpe, D. L. (2009). Effect of personal financial knowledge on college students' credit card behavior. Journal of Financial Counseling and Planning, 20(1), 19.

Rosacker, K. M. \& Rosacker, R. E. (2016). An exploratory study of financial literacy training for accounting and business majors. The International Journal of Management Education, 1-7.

Rosacker, K. M., Ragothaman, S. \& Gillispie, M. (2009). Financial literacy of freshmen business school students. College Student Journal, 43(2), 391-400.

Sarıgül, H. (2015). Finansal okuryazarlık tutum ve davranış ölçeği: Geliştirme geçerlik ve güvenirlik. Yönetim ve Ekonomi Araştırmaları Dergisi, 13(1), 200-218.

Sekaran, U. \& Bougie, R. (2016). Research methods for business: A skill building approach . United Kingdom: John Wiley \& Sons, 7. Edition.

Selcuk, E. A. \& Yilmaz, A. A. (2015). Financial literacy among Turkish college students: The role of formal education, learning approaches, and parental teaching. Psychological Reports, 115(2), 351-371.

Suwanaphan, S. (2013). Personal financial literacy of academic support-employee in Chiang Mai-University. Proceedings from Management-Knowledge and Learning International Conference, (s. 1061-1065). Zadar, Croatia.

Şamiloğlu, F., Kahraman, Y. E. \& Bağcı, H. (2016). Finansal okuryazarlık araştırması: Erciyes Üniversitesi öğrencileri üzerinde bir uygulama. Uluslararası Yönetim İktisat ve İsletme Dergisi, (30), 308-318.

Tuna, G., \& Ulu, M. O. (2016). Üniversite öğrencilerinin finansal okuryazarlık düzeylerini etkileyen faktörlerin belirlenmesi: İşletme bölümü öğrencileri üzerine bir araştırma. Uluslararası Yönetim İktisat ve İşletme Dergisi, (30), 128-141.

Volpe, R. P., Chen, H. \& Pavlicko, J. J. (1996). Personal investment literacy among college students: A survey. Financial Practice and Education, 6(2), 86-94.

Volpe, R. P., Kotel, J. E. \& Chen, H. (2002). A survey of investment literacy among online investors. Journal of Financial Counseling and Planning, 13(1), 1.

Worthington, A. (2006). Predicting financial literacy in Australia. Financial Services Review, 59-79. 
Xiao, J. J., Ahn, S. Y., Serido, J. \& Shim, S. (2014). Earlier financial literacy and later financial behaviour of college students. International Journal of Consumer Studies, 38(6), 593-601.

Xiao, J. J., Shim, S., Barber, B. \& Lyons, A. (2007). Academic success and well-being of college students: Financial behaviors matter (TCAI Report). Human Development and Family Studies.

Yew, S. Y., Yong, C. C., Cheong, K. C. \& Tey, N. P. (2017). Does financial education matter? ducation literacy among undergraduates in Malaysia. Institutions and Economies, 43-60. 
